\title{
EL FRANCISCANISMO EN LA CASTILLA DEL SIGLO XIII. UNA APROXIMACIÓN BIBLIOGRÁFICA ${ }^{1}$
}

\author{
FIDEL REVILLA GARCÍA \\ Universidad Complutense. Madrid
}

\begin{abstract}
SUMARIO
1. Situación precedente a la llegada de la orden franciscana en España. La orden franciscana en España.- 2. Provincias y conventos franciscanos.- 3. Exposiciones de la Regla y Régimen de personas.- 4. Estudios, Bibliotecas y Escuela franciscana.- 5. Espiritualidad, Hagiografía, Mariología y Escritores.- 6. Episcopologio franciscano y otros personajes franciscanos.7. Franciscanismo y Monarquía.- 8. Apostolado y Misiones franciscanas.9. Clarisas.- 10. Tercera orden franciscana seglar (OFS).- 11. Arte, Poesía y Música.- 12. Conclusiones.
\end{abstract}

\begin{abstract}
'A continuación se indican las abreviaturas de las publicaciones periódicas y colecciones que con más frecuencia se citan a lo largo del artículo: "AFH": Archivum Franciscanum Historicum (Grottaferrata, Italia); "AIA": Archivo Ibero Americano. PP Franciscanos (Madrid); "AL": Archivos Leoneses (León); "Ant": Antonianum (Roma); "BCMO": Boletín de la Comisión de Monumentos de Orense (Orense); "BIFG": Boletín de la Institución Fernán González (Burgos); "BRAG": Boletín de la Real Academia Gallega (La Coruña); "BRAH": Boletín de la Real Academia de la Historia (Madrid); "BSCEx": Boletín de la Sociedad Castellana de Excursiones (Valladolid); "CF": Collectanea Franciscana (Roma); "CFR": Cuadernos Franciscanos de Renovación (Santiago de Chile); "DHEES": Diccionario de Historia Eclesiástica de España. Suplemento, dir. por G. Aldea, T. Marín y J. Vives, 4 vols., Madrid, 1979-1982; "EF": El Eco Franciscano (Santiago de Compostela); "EFr": Estudios Franciscanos (Barcelona); "EtFr": Etudes Franciscaines (París); "ExpFran": Sociedad Española de Amigos del Arte. Exposición franciscana, (Barcelona, 1927); "Hisp": Hispania (Madrid); "LC": La Cruz (Madrid); "Mau": Mauritania (Tánger); "Mur": Murgetana (Murcia); "REDC": Revista Española de Derecho Canónico (Madrid); "RHCEE": Repertorio de Historia de Ciencias Eclesiásticas en España, 9 vols., Salamanca, desde 1967; "Salm": Salmanticensis (Salamanca); "VV": Verdad y Vida. PP. Franciscanos (Madrid).
\end{abstract}

"Anuario de Estudios Medievales". 27 (1997) 
El siglo XIII, dentro del ámbito de la espiritualidad, será un período de enorme trascendencia debido, fundamentalmente, a la aparición de nuevas formas de expresión religiosa. Nuevas manifestaciones que se plasmarán en corrientes de intenso fervor religioso, perfectamente encauzadas gracias a dos órdenes religiosas con un marcado carácter mendicante: la Orden Dominica u "Ordo Fratrum Predicatorum" y la Orden Franciscana u "Ordo Fratrum Minorum".

Esta última será el objeto del presente estudio, centrándonos, especialmente, en la producción bibliográfica que existe sobre la aparición y desarrollo de los "Padres Franciscanos" en la Castilla ${ }^{2}$ del siglo XIII. Una Castilla que se verá involucrada en esta "oleada de nueva espiritualidad" traída con el advenimiento de la orden franciscana a Castilla. Una aparición que, según las crónicas franciscanas, se verá motivada por la presencia física del propio san Francisco de Asís en la Península Ibérica con motivo de su peregrinación a Santiago de Compostela y su posterior iniciativa misionera en territorio musulmán.

Por este motivo, se hace imprescindible abordar una visión panorámica de la producción bibliográfica que se ha venido desarrollando en este siglo, concerniente a la presencia franciscana en el reino de Castilla, enfocada desde distintos puntos de vista. Con ello, se pretende dar líneas de investigación para posteriores trabajos, así como un estado de la cuestión que recoja los distintos trabajos que se han venido desarrollando sobre el tema que nos atañe, que nos permita iniciar y, en muchos casos, completar líneas de investigación que necesitan de una revisión partiendo de nuevos enfoques metodológicos.

Esta labor recopilatoria de bibliografía franciscana para ámbito hispánico ya fue realizada por Manuel de Castro y Castro $^{3}$ pero dándole un enfoque más general, confeccionando un auténtico vademécum de toda la bibliografía que aborda temas de franciscanismo en la Península Ibérica y en América hasta 1993 y que será la fuente primordial donde bebamos para la elaboración de este trabajo de carácter bibliográfico. Otra aportación de

\footnotetext{
"Cuando se hace referencia en este artículo a "Castilla" nos referimos al Reino de Castilla y León, comprendiendo geográficamente las dos Castillas, Galicia, Asturias, País Vasco, La Rioja, Murcia y Andalucía, a excepción del Reino Nazari de Granada.

'Manuel de CASTRO Y CASTRO, OFM, Bibliografia hispanofranciscana, Santiago de Compostela, 1994. Sería muy necesario que se realizase una segunda edición de esta obra, ordenando alfabéticamente los distintos autores que aparecen en cada epígrafe de dicha obra.
} 
indudable valor en el campo de la bibliografía franciscana de carácter general es la realizada por Tomás Sáenz de $\mathrm{Haro}^{4}$ y que, en cierta medida, recopila las nuevas aportaciones bibliográficas desde 1993 hasta 1995. También hay que destacar en estas líneas la preocupación por los temas franciscanos de distintas entidades y asociaciones, plasmada en diversos congresos y seminarios. Así, se hace necesario mencionar la celebración en Nájera, del 31 de julio al 4 de agosto de 1995, de las "VI Semanas de Estudios Medievales", referidas a espiritualidad franciscana, centrándose cronológicamente en el siglo XIII, fundamentalmente; y la celebración, para ámbito clariano, del Congreso Internacional "Las clarisas en España y Portugal", organizado en Salamanca del 20 al 25 de septiembre de 1993. Ambos tendrán un enorme valor, ya que se pusieron al día las investigaciones que se estaban efectuando sobre esta línea de investigación en relación a las órdenes mendicantes y, en concreto, a la espiritualidad franciscana y todas sus manifestaciones.

\section{SiTUACIÓN PRECEDENTE A LA LLEGADA DE LA ORDEN FRANCISCANA EN ESPAÑA. LA ORDEN FRANCISCANA EN ESPAÑA}

La orden franciscana tiene su aparición como revulsivo a una situación espiritual en continua decadencia, materializada en los monasterios y en la constante degradación de la Iglesia secular. Con la entrada en escena de esta nueva orden mendicante se dará satisfacción, de forma mucho más clara y al alcance de cualquier fiel culto o inculto, a aquellas inquietudes espirituales que el clero secular y el monástico no eran capaces de satisfacer, con plenas garantías, a un pueblo ávido de nuevas perspectivas religiosas. Esos fieles que veían la religión como algo oscuro y lejano pero, con la entrada de esta nueva orden de los Hermanos Menores, verían como se abría una fuente de luz que satisfacería sus inquietudes religiosas.

Los estudios realizados más recientes sobre la situación en que se encontraba la Iglesia regular en la Castilla del siglo XIII se los debemos a

\footnotetext{
${ }^{\dagger}$ Tomás SÁENZ DE HARO, Franciscanismo y espiritualidad. Bibliografia, "Actas de la VI" Semana de Estudios Medievales (Nájera, 1995), Logroño, 1996, pp. 301-336.
} 
Antonio Linage Conde ${ }^{5}$ y a Javier García Turza ${ }^{6}$, reflejando la situación reinante en el monacato castellano-leonés y en la sociedad peninsular de la época.

Obras de consulta inicial, para tener una visión global del acontecer histórico franciscano en Castilla, son el Diccionario de Historia Eclesiástica de España ${ }^{7}$ y la Historia de la Iglesia en España ${ }^{8}$, dirigida por García Villoslada. Pero, sin duda alguna, la base bibliográfica para comenzar cualquier trabajo relacionado con el franciscanismo castellano es la aportada por José García Oro ${ }^{9}$, realizando un análisis, muy claro y conciso, sobre la génesis del franciscanismo en la Península durante el siglo XIII, la corriente reformadora observante de los siglos XIV y XV y finalizando con una somera visión de la orden franciscana en el siglo XVI. También resultaría muy aconsejable la consulta del apéndice de la obra del P. Deodato Carbajo ${ }^{10}$ referido al origen de la orden franciscana en la Península Ibérica, ya que, en pocas páginas, hace un estudio muy aceptable de sus primeros pasos en esta área geográfica. Y para completar esta visión sumamente general, y centrándonos en el siglo XIII propiamente dicho, es necesario hacer mención a la obra de Peter Linehan ${ }^{11}$ y al artículo conjunto de Miguel Angel Ladero Quesada y José Manuel Nieto Soria ${ }^{12}$, que, aunque no se ajusten completamente a la temática franciscana, nos ofrecen una panorámica de conjunto de

\footnotetext{
${ }^{5}$ Antonio LINAGE CONDE, De los monjes a los frailes. Notas sobre la implantación de la vida religiosa medieval en el territorio castellano-leonés, "Congreso de Historia de Castilla y León (Valladolid, 1982)", Burgos, 1983, pp. 263-274 y El antiguo monacato en España a la hora de la implantación mendicante, "Arquivo Histórico Portugués", III (1983), pp. 81-114.

"Javier GaRcía TURza, De los monjes a los frailes: La coyuntura del año 1200 en la sociedad y en la Iglesia, "Actas de la VI Semana de Estudios Medievales (Nájera, 1995)", Logroño, 1996, pp. 13-28.

${ }^{7}$ Diccionario de Historia Eclesiástica de España (DHEE), dir. por Q. ALDEA, T. MARÍN y J. VIVES, 4 volúmenes, Madrid, 1972- 1975.

${ }^{8}$ Historia de la Iglesia en España, dir. por R. García Villoslada, vol. II-2, Madrid, 1979-1982, pp. 130-36.

'José GARCía ORO, OFM, El franciscanismo hispano de la Edad Media, "VV", XLV (1987), pp. 207-49. y su clásico Francisco de Asís en la España Medieval, Santiago de Compostela, 1988.

${ }^{10}$ Deodato CARBajo, OFM, Elementos de historia de la orden franciscana. Murcia, 1958. (Ver Apéndice: “Origen de la Orden franciscana en la Península Ibérica”, pp. 385-404).

"Peter Linehan, La Iglesia española y el papado en el siglo XIII, Salamanca, 1975.

${ }^{12}$ Miguel Angel Ladero Quesada y José Manuel Nieto Soria, Iglesia y sociedad en los siglos XIII al XV (ámbito castellano-leonés): Estado de la cuestión, "En la España Medieval", XI (1988), pp. 126-151.
} 
la situación de la Iglesia española y el papado en dicho siglo, además de una relación bibliográfica que puede ser útil para dar los primeros pasos en este campo de estudio.

Como ya dijimos más arriba, se tiene bastante certeza de la presencia de san Francisco de Asís en la Península y, para dar luz al respecto, surgieron las obras de los PP. Ernesto $\mathrm{M}^{\mathrm{a}}$ de Beaulieu ${ }^{13}$, Atanasio López $^{14}$, Manuel Bandín ${ }^{15}$ e Isidoro Aguado de Villapadierna ${ }^{16}$, que, aunque sean de la primera década de este siglo, son de ineludible consulta por parte del investigador para poder afrontar, con cierto éxito, esta problemática que se genera al tomar contacto con los orígenes del franciscanismo en Castilla. Pero, aunque esta entrada franciscana se produjera de la mano del propio santo fundador, no fue óbice para que la misma, y su ulterior implantación, tuviera algunas particularidades y dificultades en los primeros contactos con los monjes y obispos, que veían peligrar su situación de predominio entre los fieles como indican el P. Atanasio López ${ }^{17}$ y Antonio Linage Conde ${ }^{18}$.

Una línea de investigación de suma importancia, dentro de este apartado correspondiente a la bibliografía general franciscana en el reino de Castilla, es la que atañe al estudio de su expansión en territorio castellano ${ }^{19}$. Esta se realizaría de manera fulgurante al amparo de los muros de las ciudades, que en esta época veían incrementarse su población y su actividad

${ }^{13}$ Ernesto $\mathrm{M}^{\mathrm{a}}$ DE BEAULIEU, OFMCap, Le voyage de saint François en Espagne, "EtFr", XV (1906), pp. 388-91 y XVI (1906), pp. 60-75.

${ }^{14}$ Atanasio LÓPEZ FERNÁNDEZ, OFM, Viaje de san Francisco a España (1214), "AIA", I (1914), pp. 13-45, 257-89 y 433-68; y “AFH", VII (1914), pp. 395-96. 19-50.

${ }^{15}$ Manuel BANDín, OFM, San Francisco y la orden franciscana en España, "ExpFran”, pp.

${ }^{16}$ Isidoro AGUADO DE VILLAPADIERNA, OFMCap, La imagen de san Francisco en España, "Francesco d'Assisi nella storia", I, Roma, 1983, pp. 287-310.

${ }^{17}$ Atanasio LÓPEZ, OFM, Primicias franciscanas en España. Dificultades entre obispos, monjes y frailes, "LC", I (1910), pp. 205-8.

${ }^{18}$ Antonio LINAGE CONDE, Algunas particularidades de la implantación mendicante en la Península Ibérica, “Arquivo Histórico Dominicano Portugués” (Porto), VIII (1986), pp. 1-25; "AIA", XLVII (1987), p. 414. (Analiza el ensayo de implantación franciscana en áreas fronterizas).

${ }^{19} \mathrm{~F}$. Javier PEÑA PÉREZ, Expansión de las órdenes conventuales en León y Castilla: Franciscanos y Dominicos en el siglo XIII, "Actas de la VI Semana de Estudios Medievales (Nájera, 1992)", Logroño, 1993, pp. 179-198. Dentro de este apartado sería interesante para conocer el número de fundaciones realizadas en Europa y, más en concreto, en Castilla, consultar el artículo de Domingo CRESI, OFM, Statistica dell'ordine minoritico all'anno 1282 , AFH, LVI (1963), pp. 157-62. 
interna, y de las clases dirigentes de las mismas, así como del resto de la población. No obstante, aunque esta expansión se hiciera tan rápidamente, estaba perfectamente regulada la ubicación de los distintos conventos franciscanos en el marco espacial de la ciudad ${ }^{20}$.

\section{PROVINCIAS Y CONVENTOS FRANCISCANOS}

Tras la entrada de los Frailes Menores en el reino castellano, esta presencia quedaría encuadrada administrativamente en una Provincia Franciscana que regiría los primeros pasos de estos frailes en territorio hispano $^{21}$. Esta quedó establecida en 1217 y sería denominada "Provincia Franciscana de España", formando parte integrante de un conjunto de provincias franciscanas que se irían formando en el resto de Europa ${ }^{22}$. A su vez, dichas provincias, tendrían bajo su control una serie de custodias ${ }^{23}$, las cuales controlarían un número determinado de conventos. Esta situación duraría poco tiempo ya que, en 1233 y gracias a una enorme expansión por territorio peninsular, se dividiría en tres provincias: La "Provincia Franciscana de Santiago", que coincidiría con la primigenia provincia de España y, por consiguiente, estaría fundada en 1217, abarcando Galicia, Asturias, el antiguo reino de León y territorio extremeño; la "Provincia Franciscana de Castilla", que comprendería el actual País Vasco, Cantabria, La Rioja, Castilla, Murcia y la parte recuperada de Andalucía; y la "Provincia Franciscana de Aragón", que correspondería a los territorios de la Corona de Aragón ${ }^{24}$.

\footnotetext{
${ }^{20}$ Marta CUADRADo SÁNCHEZ, Un nuevo marco socioespacial: emplazamiento de los conventos mendicantes en el plano urbano, "Actas de la VI Semana de Estudios Medievales (Nájera, 1995)", Logroño, 1996, pp. 101-109.

${ }^{21}$ El mejor conocedor del origen de la Provincia de España y su desarrollo, hasta su posterior división, es el P. Atanasio LóPEZ FERNÁNDEZ, OFM, y su obra La provincia de España de los frailes menores. Apuntes histórico-críticos sobre los origenes de la orden franciscana en España. Santiago, El Eco Franciscano, 1915.

22Jerónimo Golubovich, OFM, Series provinciarum ordinis fratrum minorum. Saec. XIII et XIV, “AFH”, I (1908), pp. 1-22; J. MoORMAN, Medieval Franciscan Houses, Nueva York, 1983, pp. 1-533.

${ }^{23}$ MOORMAN, Medieval Franciscan., pp. 693-697.

${ }^{24}$ Atanasio LÓPEZ, OFM, División de la provincia franciscana de España en el siglo XIII, "EFr”, III (1909), pp. 29-34. “AFH”, VI (1913), pp. 413-14.
} 
Existe una gran variedad de bibliografía referida al ámbito de las provincias de Santiago y de Castilla ${ }^{25}$, pero una parte de esa bibliografía sigue, casi al pie de la letra, lo que manifiestan las distintas crónicas ${ }^{26}$ referidas a estas dos provincias, dando lugar a un enfoque histórico muy limitado y mediatizado, aunque no dejen de ser, por este motivo, una piedra de toque ineludible a la hora de enfrentarse con el estudio de estas provin$\operatorname{cias}^{27}$. Pero antes de abordar la bibliografía más específica sobre las provincias franciscanas en el reino de Castilla, es imprescindible tener una buena base que nos acerque, de forma clara, a estas nuevas realidades; $\mathbf{y}^{\prime}$ para lograr este objetivo es de obligada lectura la obra ya citada del P. José García $\mathrm{Oro}^{28}$ y el artículo, recientemente aparecido, de Adeline Rucquoi ${ }^{29}$.

Centrándonos ya en la bibliografía específica más reciente de las provincias de Santiago y Castilla, hay que destacar a los PP. Manuel de $\mathrm{Castro}^{30}$, para la provincia de Santiago, y Antolín Abad Pérez ${ }^{31}$, para la castellana. Dentro de esta línea de investigación estarían las obras, con un carácter más regional, de Javier Fernández Conde ${ }^{32}$ para Asturias, Ángel Uribe $^{33}$ para Cantabria, Ernesto García Fernández ${ }^{34}$ para el País Vasco,

\footnotetext{
${ }^{25}$ Aunque se crean tres nuevas provincias en el siglo XIII el estudio bibliográfico se realizará sobre las provincias franciscanas que se encuentran dentro de territorio castellano (Santiago y Castilla); por este motivo la bibliografía referente a la provincia franciscana de Aragón no se mencionará

${ }^{26}$ Crónica de la provincia franciscana de Santiago, 1214-1614. Por un franciscano anónimo del siglo XVIII. (Introducción, rectificaciones y notas por Manuel de Castro y Castro, OFM). Madrid, 1971; Jacobo de CASTRO, OFM, Arbol cronológico de la provincia de Santiago, (Edición facsímil por Odilio Parente, de las de Salamanca 1722 y Santiago 1727), 2 vols. Madrid, Ed. Cisneros, 1976-77; y para la provincia de Castilla destacar de forma muy especial la obra de Pedro de SAlazAR, OFM, Crónica de la provincia de Castilla, (Edición facsímil por Antolín Abad Pérez, OFM, de la de Madrid 1612), Madrid, 1977.

${ }^{27}$ Atanasio LÓPEZ FERNÁNDEZ, OFM, Los arzobispos de Santiago y la orden franciscana. Siglos XIII-XIV, "EF", XXXI (1914), pp. 592-94; y La provincia de Santiago en el siglo XIII, "EF", LIII (1936), p. 456.

${ }^{28}$ García Oro, OFM, Francisco de Asís.

${ }^{29}$ Adeline RucQuoI, Los franciscanos en el reino de Castilla, "Actas de la VI a Semana de Estudios Medievales (Nájera, 1995)”, Logroño, 1996, pp. 65-86.

${ }^{30}$ Manuel de CASTRO Y CASTRO, OFM, La provincia franciscana de Santiago. Ocho siglos de historia, Santiago, 1984; Franciscanos en Galicia, "La Gran Enciclopedia Gallega".

${ }^{31}$ Antolín ABAD PÉREZ, OFM, Los ministros provinciales de Castilla, "AIA”, XLIX (1989), pp. $327-86$

32Javier FERNÁNDEZ CONDE, La orden franciscana en Asturias. Origen y primera época, "AFH", LXXXII (1989), pp. 316 y ss. (Con apéndice documental).

${ }^{33}$ Angel URIBE, OFM, La provincia franciscana de Cantabria. I. El franciscanismo vascocántabro desde sus orígenes hasta el año 1551, Oña, 1988. (Con apéndice documental).
} 
José María Alonso del Val ${ }^{35}$ para Burgos y Germán Rubio ${ }^{36}$ y la tesis doctoral de José M. Miura Andrades ${ }^{37}$ para Sevilla.

$\mathrm{Al}$ introducirnos en la producción bibliográfica sobre los conventos franciscanos que empiezan a surgir en el siglo XIII castellano, nos percatamos de que la mayoría de la obras son un complejo mundo de elucubraciones para intentar demostrar que el convento del que se habla es el primero que se fundó en esa provincia franciscana o en la Península, e incluso afirmando que dicha fundación fue realizada por el propio san Francisco, convirtiéndose este tipo de bibliografías en una auténtica competición por buscar y demostrar que su convento es el más antiguo. Lo cierto, es que se presentan enormes dificultades a la hora de poder establecer fechas concretas de fundación de un convento debido a la falta de fuentes documentales; por este motivo, los conventos que se citan a la hora de hacer mención de su bibliografía se darán con la fecha más temprana en la que hay constancia documental de que ese convento existe. Siguiendo este método, se comprueba la existencia de una cincuentena de fundaciones para el territorio del reino de Castilla en el siglo XIII, siendo el siglo en el que mayor número de fundaciones franciscanas se realizaron en Castilla en la Baja Edad Media.

Como se ha podido observar a lo largo de este trabajo, el autor que más se ocupa de aspectos referentes al franciscanismo castellano del siglo XIII es el P. Atanasio López, OFM. Este protagonismo también se materializará en el campo de la bibliografía conventual, realizando pequeños estudios sobre los conventos más significativos fundados en dicho siglo ${ }^{38}$. A su vez,

\footnotetext{
${ }^{34}$ Ernesto GARCÍA FERnÁNDEZ, Dominicos y franciscanos en el País Vasco (siglos XIII-XIV), "Actas de la VI Semana de Estudios Medievales (Nájera, 1995)", Logroño, 1996, pp. 213-33.

${ }^{35}$ José María ALONSO DEL VAL, OFM, Los primeros conventos franciscanos de la provincia seráfica de Burgos, "Actas de la VI Semana de Estudios Medievales (Nájera, 1995)", Logroño, 1996, pp. 271-282.

${ }^{36}$ Germán RUBIO, OFM, La custodia franciscana de Sevilla. Ensayo histórico sobre sus origenes, progresos y vicisitudes (1220-1449), Sevilla, 1953.

${ }^{37}$ José M. MIURA ANDRADES, Las ordenes mendicantes en el Reino de Sevilla durante la Baja Edad Media, tesis doctoral dirigida por José Sanchez Herrero y presentada en la Facultad de Geografía e Historia de la Universidad de Sevilla en el curso 95-96. (No sólo se ocupará del estudio de la orden franciscana específicamente sino de las ordenes mendicantes en general)

${ }^{38}$ Atanasio LÓPEZ FERNÁNDEZ, OFM, Primicias franciscanas de España. Frailes Menores en Astorga, (c.1280) (a continuación del título se indicará el año de fundación o del primer documento que hace mención de la existencia de dicho convento) "LC", 1908(2), pp. 49-50 y 1910(1), pp. 199-203; Primicias franciscanas de España. Convento de Ayllón, (1220), "LC", 1908(2), pp. 512-23; Primicias franciscanas de España. Convento de La Bastida (Toledo), (1219), "LC", 1908(2), pp. 131-37; Primicias franciscanas de España. Convento de San
} 
hay que hacer mención a los trabajos de Sánchez Doncel ${ }^{39}$, Layna Serrano $^{40}$, Herrera Casado ${ }^{41}$, el P. Omaechevarría ${ }^{42}$, Linehan ${ }^{43}$, Escribano Castilla $^{44}$, Velasco ${ }^{45}$, Sáinz $\mathrm{Ripa}^{46}$, Carrasco Lazareno ${ }^{47}$, el P. Pína-

Francisco de Benavente, (1270), “LC”, 1911(2), pp. 266-67; Convento de Betanzos. Siglos XIIIXV, (1289), "EF”, XXXI (1914), pp. 245-58 y 376-77; Primicias franciscanas de España. Convento de Ciudad Rodrigo, (1220), "LC", 1908(2), pp. 515-16; Convento de San Francisco, de La Coruña. (Siglos XIII al XV), (c.1262), "BRAG", VIII (1914-15), pp. 1-7 y 170-75; Primicias franciscanas de España. Convento de León, (1230), "LC", 1908(2), pp. 50-55 y 1911(2), pp. 250-66; Convento de San Francisco de León, "AIA", IX (1918), pp. 5-37; Primicias franciscanas de España. Convento de Lugo, (a.1282), "LC", 1910(1), pp. 197-99; Primicias franciscanas de España. Convento de Orense, (c.1249), "LC", 1908(2), pp. 516-23; ¿En qué año fue fundado el convento de franciscanos de Orense?, "BCMO", XI (1936), pp. 49-56 y 73-80; Primicias franciscanas de España. Convento de Palencia, (1240), "LC", 1910(2), pp. 424-26; Primicias franciscanas de España. Convento de Pontevedra, (1274), "LC", 1909(2), pp. 199-200; Primicias franciscanas de España. Convento de Ribadavia, (1250), "LC", 1910(2), pp. 144-46; Primicias franciscanas de España. Convento de Ribadeo, (c. 1287), "LC", 1910(2), pp. 143-44; Primicias franciscanas de España. Convento de San Francisco de Compostela, (c.1222), "LC", 1908(1), pp. 226-37, 330-39 y 436-42; Recuerdos de san Francisco en Santiago (siglo XIII), "La provincia de España de los frailes menores", Santiago, 1915, pp. 333-43; Convento de San Lorenzo, en Santiago de Compostela, (1222-30), "EFr", II (1908), pp. 36-39; Convento de San Lorenzo de Trasouto, extramuros de la ciudad de Santiago de Compostela, "AIA”, XXXVI (1933), pp. 386-415; Primicias franciscanas de España. Convento de Segovia, (1250-70), "LC", 1909(1), pp. 138-48; Primicias franciscanas de España. Convento de Soria, (c.1230), "LC", 1909(1), pp. 45-56 y 131-41; Primicias franciscanas de España. Convento de San Francisco de Toro, (c.1290), “LC”, 1911(2), pp. 140-50; Primicias franciscanas de España. Convento de Villafranca del Bierzo, (1214), "LC", 1910(1), pp. 203-5; Primicias franciscanas de España. Convento de Vitoria, (c.1236), "LC", 1908(2), pp. 131-37; Primicias franciscanas de España. Conventos de Vivero y Lugo, (c. 1277 y c.1282), "LC", 1910(1), pp. 196-99.

${ }^{39}$ G. SÁNCHEZ DONCEL, San Francisco de Asís en España y en Alcocer (Guadalajara), (1252), "Wad-al-Hayara", X (1983), pp. 359-63.

${ }^{40}$ Francisco Layna Serrano, Historia de la villa de Atienza, (1266), Madrid, 1945, pp. 132-33.

${ }^{41}$ Antonio Herrera CASADo, Monasterios y conventos en la provincia de Guadalajara, Guadalajara, 1974.

${ }^{42}$ Ignacio OMAEChEVARRía, OFM, San Francisco en Burgos hace 750 años, (c.1230), "BIFG", XLIII (1964), pp. 363-80.

${ }^{43}$ Peter LINEHAN, A tale of two cities: capitular Burgos and mendicant Burgos in the thirteen century, "Church and city, 1000-1500th" (Essays in Honour of Christopher Broode), Cambridge University Press, 1992

${ }^{44} \mathrm{~A}$. EsCRIBANo CASTILla, Fundaciones franciscanas en la Córdoba medieval, (1246), “Andalucía medieval”, Córdoba, 1982, pp. 320-30.

${ }^{45}$ B. VELASCO, El convento de San Francisco de Cuellar, (1235), “AIA”, XXXIII (1973), pp. 269-300.

${ }^{46}{ }^{6}$ Eliseo SÁInz RIPA, Primer franciscanismo en Logroño, (c. 1270), “Actas de la VI Semana de Estudios Medievales (Nájera, 1995)”, Logroño, 1996, pp. 235-238. 
ga $^{48}$, el P. Meseguer Fernández ${ }^{49}$, Quintana Prieto ${ }^{50}$, Agapito y Revi$1 \mathrm{la}^{51}$ y Fernández del $\mathrm{Hoyo}^{52}$.

\section{EXPOSICIONES DE LA REgLA Y RÉGIMEN DE PERSONAS}

Como ya dijimos anteriormente, aunque la penetración franciscana, y su posterior desarrollo, en Castilla fue muy rápido, no por ello fue óbice para que esta serie continuada de asentamientos de frailes menores estuvieran, en algún momento concreto, desatendidos normativamente. Ya desde los inicios de esta orden mendicante estuvo perfectamente regulada mediante la elaboración de una Regla; reglamentación realizada por Francisco de Asís y posteriormente revisada por distintos miembros de la orden, siendo aprobadas las distintas revisiones y modificaciones por el pontificado.

Aunque no tengamos un autor concreto que haya realizado algún trabajo referente a este línea de investigación para el siglo XIII castellano, no podemos olvidarnos de la labor desarrollada en esta temática por el P. Fidel de Elizondo Pamplona, OFMCap, ocupándose, por una lado, de la obligatoriedad de las reglas, y su estricto cumplimiento, para los siglos XII y XIII, pudiendo ser muy útil a la hora de querer afrontar este mismo tema pero para ámbito castellano, ya que, el autor, da una base fundamental que indica el camino a seguir por el investigador desde una perspectiva cronológica más amplia ${ }^{53}$. Por otro lado, también se ha ocupado, en algún trabajo más específico, de la reglamentación franciscana del siglo XIII pero

\footnotetext{
${ }^{47}$ María Teresa CarRasco LaZARENo, Los conventos de San Francisco y de Santo Domingo de la villa de Madrid (siglos XIII-XV). Breves consideraciones históricas, jurídicas y diplomáticas, (c.1214?), "Actas de la VI Semana de Estudios Medievales (Nájera, 1995)", Logroño, 1996, pp. 239-254.

${ }^{48}$ Epifanio PinAga, OFM, Testamento de la infanta Da Blanca de Molina, fundadora del convento de San Francisco, de Molina de Aragón. Año 1293, "AIA", 1927, pp. 394-400.

${ }^{49}$ Juan MESEGUER FERNÁNDEZ, OFM, Documentos históricos diversos. Los franciscanos en Murcia y Alicante, 1282, “AIA”, XXXII (1972), pp. 511-16.

${ }^{50}$ Augusto QUINTANA PRIETO, San Francisco, de Sahagún, primeros pasos de este convento franciscano, (1257), “AL”, XXXVI (1982), pp. 109-57. (Con apéndice documental).

${ }^{51} J u a n$ AgAPITO Y REVILLA, Tradiciones de Valladolid. La leyenda del convento de San Francisco, (c.1230), "BSCEx", VI (1913-14), pp. 367-70.

${ }^{52}$ M.A. FERNÁNDEZ DEL HOYO, El convento de San Francisco de Valladolid. Nuevos datos para su historia, "Boletín del Seminario de Estudios de Arte y Arqueología", LI (1985), pp. 411-438.

${ }^{53}$ Fidel de Elizondo PAMPlONA, OFMCAP, Obligatoriedad de las reglas en los siglos XII $y$ XIII, “REDC”, VIII (1953), pp. 761-93.
} 
desde una óptica globalizadora, descartando el referirse a un área geográfica concreta $^{54}$.

Con respecto a la bibliografía existente sobre el Régimen de personas para el siglo XIII castellano, la situación no es más halagüeña que para la anterior línea de investigación, ya que no hay, por lo menos hasta la fecha, ninguna obra relacionada con este tema para este ámbito cronológico y geográfico. Quizás, el motivo sea la escasez documental o, lo más probable, la falta de interés que pueda suscitar a los investigadores. Debido a esta enorme laguna, se hace imprescindible la elaboración de estudios en profundidad de los regímenes de personas para las distintas provincias franciscanas existentes en Castilla y, muy en particular, para los conventos franciscanos más importantes del período (Santiago, Salamanca, Burgos, etc.); y la elaboración concienzuda de buenas relaciones prosopográficas de los distintos conventos y provincias donde se centre dicha investigación. A modo de ejemplo baste el trabajo, aunque muy general, pero localizado en el siglo que nos ocupa, del P. Julio Micó, OFMCap ${ }^{55}$.

\section{ESTUdios, BibliotecAS Y EsCUELA FRANCISCANA}

Otra línea de investigación susceptible de ser resaltada debe ser, forzosamente, todo lo que concierne a la labor intelectual desarrollada por la orden franciscana castellana a lo largo del siglo XIII. Una labor que, aunque no fue tan prolífica como pudo haber sido la efectuada por la orden dominica, si tuvo su papel importante dentro de la producción intelectual de la época. Una producción de la que, se afirmaría, no se la dio una gran importancia desde los tiempos iniciales de Francisco de Asís, pero como se puede comprobar esta si tendrá un papel de relevancia, no sólo para Italia sino para el resto de países en el que el franciscanismo penetró con fuerza, y muy especialmente en Castilla, dando lugar a la creación de Estudios, bibliotecas y a una Escuela franciscana propiamente dicha.

\footnotetext{
${ }^{54}$ Fidel de ElizONDO PAMPLONA, OFMCAP, Obligatoriedad de la regla franciscana (siglo XIII), “EFr”, LVI (1955), pp. 345-56; LVII (1956), pp. 73-98. (Incluye expositores de la regla desde Hugo de Digne a David de Augsburgo).

${ }^{55} J u l i o$ Micó, OFMCAP, Los hermanos laicos en la evolución de la fraternidad primitiva, "EFr", LXXVII (1976), pp. 19-64.
} 
La aparición de Estudios en distintos conventos será la manifestación más fehaciente del desarrollo y progreso de una comunidad conventual en una ciudad. Su análisis ya fue abordado por el perenne P. Atanasio Lópe $^{56}$, ejecutándolo desde una perspectiva muy general y ubicándolo cronológicamente en los siglos XIII y XIV. También, dentro de su labor investigadora, se va a ocupar de estos asuntos, aunque mucho más actual que el anterior, el P. Isaac Vázquez Janeiro, haciendo hincapié en el estudio como elemento esencial de la vocación franciscana ${ }^{57}$.

Para las provincias franciscanas castellanas, hay que lamentar que no se haya producido ningún estudio localizado, geográficamente, en la provincia franciscana de Castilla para este siglo. Aunque, para el ámbito de la provincia de Santiago no sea mucho más favorable sí encontramos algunos estudios que, por lo menos, orientan al investigador para futuras investigaciones en este campo ${ }^{58}$.

De la misma forma que ocurre para el caso de los Estudios franciscanos va a suceder para todo lo concerniente a las bibliotecas franciscanas. Es decir, que los pocos trabajos que se tienen hasta ahora se han ocupado casi exclusivamente de bibliotecas situadas en la provincia de Santiago dejando de lado las existentes en la provincia de Castilla. Esto puede ser síntoma de que no se haya encontrado documentación referente a bibliotecas de esta provincia o, tal vez, que su estudio no tenga relevancia debido a la poca importancia que puedan tener las bibliotecas franciscanas castellanas para este siglo. De esta manera, para la provincia de Santiago

\footnotetext{
${ }^{56}$ Atanasio LÓPEZ FERNÁNDEZ, OFM, Los estudios durante los siglos XIII y XIV entre los franciscanos de España, "EF", XXXVIII (1921), pp. 238-39, 333-35, 428-30 y 453-56.

${ }^{57}$ Isaac VÁZQUEZ JANEIRO, OFM, El estudio y la vocación franciscana, "VV", XLIX (1991), pp. 33-58; y Los estudios franciscanos medievales en España, "Actas de la VI a Semana de Estudios Medievales (Nájera, 1995)”, Logroño, 1996, pp. 43-64.

${ }^{58}$ Crónica de la provincia franciscana de Santiago, 1214-1614, (Edic. de Manuel de Castro y Castro, OFM), Madrid, 1971. Para los estudios los capítulos XLIV-LVII; M. RODRíGUEZ Pazos, Los estudios en la Provincia Franciscana de Santiago, Madrid, 1967; Luis García BALLESTER, Naturaleza y ciencia en la Castilla del siglo XIII. Los orígenes de una tradición: los Studia franciscano y dominico de Santiago de Compostela (1222-1230), "Actas de la VI" Semana de Estudios Medievales (Nájera, 1995)”, Logroño, 1996, pp. 145-169.
} 
tenemos los trabajos realizados por los PP. Castro y Castro ${ }^{59}$, García y García y Vázquez Janeiro ${ }^{60}$.

De suma importancia será la aparición de una Escuela franciscana que orientará y será el soporte ideológico de esta nueva orden mendicante surgida en este siglo. Pero, aun ejerciendo un gran papel para todo lo que afecta a las directrices filosóficas y teológicas de la orden, no tenemos una obra, o serie de trabajos, que se ocupe del estudio de esta Escuela franciscana para Castilla en el siglo XIII. Todas las obras que existen se decantan por aspectos muy generales y ámbitos geográficos muy amplios. Así, para la producción filosófica hay que citar el trabajo del P. López de Munain ${ }^{61}$ y Pérez Arjós ${ }^{62}$, que aunque se dediquen a problemáticas que estaban latentes en el franciscanismo europeo de la época, no por ello deja de ser interesante, ya que afectará en igual medida al franciscanismo castellano coetáneo.

En el plano teológico la creación bibliográfica seguirá los mismos derroteros que para el plano filosófico, pero con la salvedad de que existen obras de carácter general que tratarán, de manera muy somera, la elaboración de una producción teológica franciscana en Castilla ${ }^{63}$. Sin embargo, para temas más específicos de teología la producción es aún menor, pudiendo destacarse solamente el trabajo de Javier Garrido sobre el tema de la piedad para la escuela franciscana en genera ${ }^{64}$.

\footnotetext{
${ }^{59}$ Manuel de CASTRO Y CASTRO, OFM, La biblioteca de los franciscanos de Val de Dios, de Santiago (1222-1230), "AIA", LIII (1993), pp. 151-62.

${ }^{60}$ Antonio GaRCíA Y GARCíA e Isaac VÁzQUEZ JANEIRO, OFM, La Biblioteca del arzobispo de Santiago de Compostela Bernardo II (+1240), “Ant”, LXI (1986), pp. 540-68.

${ }^{61} \mathrm{R}$. LÓPEZ DE MUNAIN, OFM, El problema de la libertad y los doctores franciscanos del siglo XIII, "VV", V (1947), pp. 283-307.

${ }^{62} \mathrm{~B}$. PÉREZ ARJós, La actividad cognoscitiva en los escolásticos del primer período postomista, 1275-1320, "Pensamiento", IV (1948), pp. 167-202.

${ }^{63}$ Bonifacio Palacios y Bartolomé PARERA, Historia de la teología española. I. Desde sus orígenes hasta el siglo XVI, (Dir. Melquíades Andrés, OFM), Madrid, 1983, pp. 409-494; Javier FERNÁNDEZ CONDE, Teología, espiritualidad y filosofía, "Historia de España" (Dir. por Ramón Menéndez Pidal), XVI, pp. 439 y ss. Las referencias sobre la escolástica peninsular en el siglo XIII y sobre la escuela franciscana en las pp. 470 y ss.

${ }^{64} \mathrm{Javier}$ GARRIDO, OFM; El "argumentum ex pietate" en la escuela franciscana del siglo XIII, "VV", XXVI (1968), pp. 291-353.
} 


\section{ESPIRITUALIDAD, HAGIOGRAFÍA, MARIOLOGÍA Y ESCRITORES}

La tónica general ęn el campo bibliográfico, referido a esta línea de investigación, se vuelve a repetir. No encontramos ningún trabajo para ámbito castellano, propiamente dicho, en el siglo XIII que toque temas de espiritualidad, mientras que para los otros campos las referencias bibliográficas son muy escasas.

Imprescindible para una primera aproximación bibliográfica en el campo de la espiritualidad franciscana, es la consulta de obras de carácter general que nos irán abriendo puertas y dirigiendo nuestros estudios por caminos más seguros. Así tenemos el trabajo de Ortega Carmona, relacionando el franciscanismo del siglo XIII con el humanismo que, como consecuencia, traerá consigo $0^{65}$, y la obra de Moliner que puede ser considerada como un pequeño manual de iniciación para estudiar la espiritualidad mendicante medieval ${ }^{66}$.

Sobre el problema de la pobreza, la inexistencia de obras para el ámbito que nos atañe es absoluta, debido a este motivo sólo se podrá hacer mención al trabajo, también con una clara visión general, de Sebastián López, centrando su investigación en la pobreza como cuerpo motor de la propia espiritualidad de san Francisco ${ }^{67}$. Para finalizar este apartado referido a los trabajos sobre espiritualidad franciscana, es importante destacar los estudios realizados sobre liturgia franciscana en sus comienzos, pero seguimos en una completa oscuridad motivada por la falta de bibliografía sobre el tema para Castilla. Aun así, no podemos dejar pasar, como obra de referencia, el trabajo de Le Carou ${ }^{68}$ sobre el oficio divino y sus orígenes en el siglo XIII; aunque no haga referencia al caso castellano si puede ser bastante útil a la hora de iniciarse en esta temática enmarañada de la liturgia franciscana.

\footnotetext{
${ }^{65}$ Alfonso ORTEGa CARMONA, OFM, Franciscanismo y humanismo del siglo XIII, "VV", XLI (1983), pp. 29-43. (Se habla de "Humanismo de integración social").

${ }^{66}$ José María MoLINER, Espiritualidad medieval. Los mendicantes, Burgos, 1974.

${ }^{67}$ Sebastián LÓPEZ, OFM, La pobreza en el pensamiento y en la actividad de san Francisco $y$ de los primeros franciscanos, "Confer" (Madrid), XII (1973), pp. 279-85.

${ }^{68} \mathrm{~A}$. LE CAROU, OFM, L'office divin chez les frères mineurs au XIII siècles. Son origin, sa destinée, París, 1928, XXXVI. (Se analiza el Breviario franciscano y su influencia en la liturgia universal).
} 
Introduciéndonos en la bibliografía hagiográfica, hay que resaltar su riqueza producida, fundamentalmente, por la aportación de los propios cronistas de la orden, ya que en todas sus crónicas otorgarán un lugar especialmente destacado a todo lo referente a la existencia de santos en su provincia para, de esta manera, poder resaltar el valor y la importancia de la misma ${ }^{69}$. Estos santos se venerarán, sobre todo, como mártires debido a los intentos de conversión de los musulmanes de Al-Andalus y, fundamentalmente, de Marruecos. Dentro de este santoral franciscano quien adquieren más fama y veneración son los franciscanos que fueron a adoctrinar a los musulmanes de Marruecos, en 1220, y que perecerían como mártires ${ }^{70}$.

La aportación franciscana en el contexto mariológico será fundamental en toda la Edad Media, siendo uno de los pilares básicos que sustentarán su espiritualidad, dando un importante impulso al dogma inmaculista. Pese a esta importancia, las obras sobre mariología para ámbito castellano son prácticamente inexistentes, pudiendo únicamente hacer referencia al trabajo, como siempre muy general, de Alejandro de Villalmonte ${ }^{71}$ sobre la aportación franciscana al desarrollo de este dogma de la Inmaculada para los siglos iniciales del franciscanismo.

La nómina de escritores franciscanos, que se dedicarán a estos temas de espiritualidad y a otros puramente científicos, para ámbito castellano no es excesivamente grande, destacando especialmente a Desiderio (fl. 1246) ${ }^{72}$, al gallego Gonzalo de Balboa $(\dagger 1313)^{73}$, Pedro Gallego, confesor de

\footnotetext{
${ }^{69}$ Jacobo de CASTRO, OFM, Crónicas Franciscanas de España. Primera parte del arbol chronológico de la Provincia de Santiago I y II, Salamanca, 1722; Santiago, 1727 (Ed. Facsímil, Madrid, 1976). Manuel de CASTRO Y CASTRO, OFM, Crónica de la Provincia Franciscana de Santiago, 1214-1614. Por un franciscano anónimo del siglo XVII, (Ed. Facsímil, Madrid, 1971). Damián CORNEJO, OFM, Chrónica Seráphica, I, Madrid, 1682/1698. F. GONZAGA, OFM, De origine Seraphicae Religionis Franciscanae eiusque progressu I y II, Roma, 1587 y Venecia, 1603. Pedro de SALAZAR, OFM, Corónica y Historia de la fundación y progreso de la provincia de Castilla de la Orden del bienaventurado padre San Francisco, (Ed. Facsímil por Antolín Abad Pérez, OFM, de la de Madrid, 1612), Madrid, 1977. J. TORRUBIA, OFM, Chronica Seraphica, Roma, 1756. Alfonso VÁzQUEZ DE TOLEDO, OFM, Historias de la Provincia Franciscana de Castilla, Manuscrito 3.840 de la Biblioteca Nacional.

${ }^{70}$ Andrés IVARS, OFM, Los mártires de Marruecos de 1220 en la literatura hispano-lusitana, "AIA", XIV (1920), pp. 344-81.

"Alejandro de VILLALMONTE, OFMCAP, Contribución de la teología franciscana al desarrollo del dogma de la Inmaculada: siglos XIII y XIV, "Salm", I (1954), pp. 688-721.

${ }^{72}$ LÓPEZ FERNÁNDEZ, OFM, La provincia de España, pp. 380-88.

${ }^{73}$ Isaac VÁZQUEZ JANEIRO, OFM, Aportaciones histórico-literarias a la historia del pensamiento medieval en España, “Ant”, XLVII (1972), pp. 644-646.
} 
Alfonso X y primer obispo de Cartagena (1250-1267) ${ }^{74}$, con su "Liber de animalibus", "De scientia domestica" o "De regitiva domus" 75 y la "Summa Astronomica"76; y, sobre todo, Juan Gil de Zamora $(\dagger 1318)^{77}$ que jugaría un importante papel en la corte del Rey Sabio, siendo ayo y preceptor del futuro Sancho IV ${ }^{78}$; destacando su "Historia Naturalis"79 y el "Liber de preconiis Hispaniae" 80 dedicada a Sancho IV. Esta nómina de autores castellanos se completará con otros que, aunque no fueran naturales del reino castellano, tendrían una enorme influencia en la espiritualidad franciscana de Castilla en el siglo XIII. Los más destacados serían el beato Gil de Asís $(\dagger 1261)^{81}$, san Buenaventura de Bagnorreggio $(\dagger 1274)^{82}$ y Juan de Gales $(\dagger 1285)^{83}$.

\section{EPISCOPOLOGIO FRANCISCANO Y OTROS PERSONAJES DE LA ORDEN}

El rápido ascenso, en el prestigio social, de los miembros de la orden franciscana se verá materializado con la subida, en un buen número de casos, a la silla episcopal de las distintas sedes existentes en la Castilla de

\footnotetext{
${ }^{74}$ Isaac VÁZQUEZ JANEIRO, OFM, Aportaciones histórico-literarias, “Ant”, XLVII (1972), p. 682.

${ }^{75}$ A. PElzer, Pierre Gallego, Franciscain et premier êvêque de Carthagène (1250-1267), "Miscellanea Francesco Ehrle", 1, Cità del Vaticano, 1924, pp. 407-456.

${ }^{76} \mathrm{G}$. MELANI, Un frammento inedito della "Summa Astronomica" del vescovo francescano Pietro Gallego, "Studi Francescani", XXV (1943), pp. 78-89.

${ }^{77}$ Fernando FELIX LOPES, Franciscanos de Portugal antes de formaren provincia independiente. Ministros provinciais a que obedeciam, "AIA", XLV (1985), pp. 407-411.

${ }^{78}$ Joseph F. O'Callaghan, El rey Sabio. El reinado de Alfonso X de Castilla, Sevilla, 1996, p. 179.

${ }^{79}$ Johannis AEGIDII ZAMORENSIS, Historia Naturalis, (Introducción, edición crítica, traducción castellana e índices por Avelino Domínguez García y Luis García Ballester), III Vol., Edit. Junta de Castilla-León, 1994. (Para la figura de Juan Gil de Zamora ver el estudio introductorio, pp. 17-96).

${ }^{80}$ Johannis AEGIDII ZAMORENSIS, De preconiis Hispaniae, (Ed. Manuel de Castro y Castro), Universidad de Madrid, 1955.

${ }^{81}$ Atanasio LóPEZ FERNÁNDEZ, OFM, Viaje del beato Gil a España, “EF”, XXII (1905), pp. $437-43$.

${ }^{82}$ Isaac VÁZQUEZ JANEIRo, OFM, San Buenaventura y España, “Ant”, LI (1976), pp. $302-$ 7. (Se habla de contactos con Juan Gil de Zamora siendo, san Buenaventura, ministro general de la orden).

${ }^{83}$ Conrado GuARdiola Alcocer, La influencia de Juan de Gales en España, “Ant”, LX (1985), pp. 99-119.
} 
la época. Un ascenso motivado por el carisma y la importante labor espiritual que los Padres Menores desarrollarán en las conciencias de las capas más bajas del engranaje social, así como entre los sectores más altos de dicha sociedad. La mayoría de las adjudicaturas de los episcopados castellanos, en beneficio de los franciscanos, serán producto de las distintas iniciativas emanadas desde la corte o desde círculos nobiliarios.

Como podemos apreciar, esta línea de investigación es de una gran relevancia para poder comprender como cambia, a raíz de la aparición de estas órdenes mendicantes, el origen de los obispos castellanos y, por tanto, su concepción de la política episcopal en diversos aspectos: espiritualidad, estudios, relaciones con otros grupos sociales, etc. Aún así, no poseemos una abundante bibliografía de carácter general que profundice en esta temática; lo poco que tenemos pertenece al ya mencionado P. Atanasio López $^{84}$ para el episcopado marroquí y a Pablo Antón Sole ${ }^{85}$, abordando la situación de la Iglesia gaditana, haciendo referencia a la procedencia de los distintos obispos que dirigirán los devenires de la susodicha Iglesia.

Sin embargo, para el estudio de los distintos obispos castellanos de procedencia franciscana, si se han realizado diversos estudios de cierta entidad que nos pueden orientar a la hora de realizar estudios más completo de los mismos, ya que estos estudios fueron hechos a principios de este siglo con las limitaciones que para el historiador de la época esto supuso. Así, tenemos trabajos del P. Atanasio López sobre la figura de Fr. Fernando Alvarez, obispo de Oviedo ${ }^{86}$; Fr. Fernando de Covarrubias, obispo de Burgos $^{87}$; del ya antes mencionado Fr. Pedro Gallego, obispo de Cartagena $^{88}$; de Fr. Juan Martínez, obispo de Cádiz ${ }^{89}$; Fr. Pedro Pérez, obispo

${ }^{84}$ Atanasio LÓPEZ FERNÁNDEZ, OFM, Los obispos de Marruecos desde el siglo XIII, "AIA", XIV (1920), pp. 399-502; Obispos en el Africa septentrional desde el siglo XIII, Tánger, 1941, pp. $1-53$.

${ }^{85}$ Pablo ANTÓN SOLÉ, La Iglesia gaditana en el siglo XIII, "Cádiz en el siglo XIII. Actas de las Jornadas conmemorativas del VIII Centenario de la muerte de Alfonso el Sabio", Cádiz, 1983 , pp. 37-48. (Menciona obispos de procedencia franciscana).

${ }^{86}$ Atanasio LóPEZ FERNÁNDEZ, OFM, Fr. Fernando Alvarez, obispo de Oviedo (1294), "LC", 1910 (2), p. 430.

${ }^{87}$ Atanasio LÓPEZ FERNÁNDEZ, OFM, Fr. Fernando de Covarrubias, obispo de Burgos, 1280-1299, "LC", 1910 (1), pp. 330-34. "EF”, LIII (1936), p. 88. “AIA", XXVII (1927), pp. 115-16; XXIX (1928), pp. 119-23.

${ }^{88}$ Atanasio LÓPEZ FERNÁNDEZ, OFM, Fr. Pedro Gallego, primer obispo de Cartagena (1250-1267), “EF”, LIII (1936), p. 20. 
de Badajoz ${ }^{90}$; Fr. Samuel, ministro provincial de Castilla y obispo de Nicastro ${ }^{91}$ y de Fr. Domingo Suárez, obispo de Ávilaa2. Estos trabajos, en algunos casos, serán completados con las diversas aportaciones de Demetrio Mansilla ${ }^{93}$ para el episcopado de Burgos y Juan Torres Fontes ${ }^{94}$ para el episcopado de Cartagena.

Dentro de este apartado, ha sido necesario considerar la existencia de diversos personajes franciscanos que tuvieron un papel destacable en este siglo de forja y consolidación de la Orden de los Menores en territorio castellano. De esta manera, se hace inevitable consultar al fecundo P. Atanasio López para valorar el papel desempenado por personajes como Fr. Benincasa de Todi ${ }^{95}$, Fr. Lope (compañero de san Francisco), Fr. Pedro "español" 96 , Fr. Esteban Alonso Domínguez y Fr. Juan (lector de León) ${ }^{97}$. Es más que probable la existencia de otros personajes de la Orden que también aportaron su inestimable granito de arena en la enorme tarea de cimentación y consolidación del edificio franciscano en Castilla, pero por la falta de estudios, posiblemente entorpecidos por la inexistencia de fuentes, determina que muchos de estas figuras estén abocadas al silencio y a la oscuridad historiográfica.

\footnotetext{
${ }^{89}$ Atanasio LÓPEZ FERNÁNDEZ, OFM, Fr. Juan Martínez, primer obispo de Cádiz (12671278), de Idcinha (1278-1301), "EF", XXVI (1909), pp. 142-45, 388-89: LIII (1936), p. 114. "Mau”, IX (1936), pp. 132-34, 163-65, 197-98. 229-31, 257-59 y 289-9i.

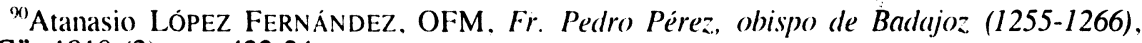
“LC", 1910 (2), pp. 422-24.

"Atanasio LÓPEZ FERNÁNDEZ, OFM, Fr. Samuel, ministro provincial de Castilla y obispo de Nicastro, 1252-?, "LC", 1910 (1), pp. 337-39. "EF". LIII (1936), p. 140.

${ }^{92}$ Atanasio López Fernández. OFM, Fr. Domingo Suárez, obispo de Ávila, 1263-1273, "EFr", II (1908), pp. 590-95. "AFH", VI (1913), p. 378.

${ }^{93}$ Demetrio Mansilla, Episcopologio de Burgos. Siglo XIII, "Hispania Sacra", IV (1951), pp. 313-333. (Para Fr. Fernando de Covarrubias pp. 331-333).

${ }^{94} J$ uan TORRES FONTES, El obispado de Cartagena en el siglo XIII, "Hisp", XIII (1953), pp. 356-88 (para Fr. Pedro Gallego).

${ }^{95}$ Atanasio LóPEZ FERnÁNDEZ, OFM, Primicias franciscanas en España. Fr. Benincasa de Todi, "LC", 1907 (2), pp. 25-33. (Fr. Benincasa entra en España acompañando a Fr. Juan Parente).

${ }^{9}$ Atanasio LóPEZ FERnÁNDEZ. OFM, Primicias franciscanas en España. Fr. Lope, compañero de san Francisco. Fr. Pedro, llamado español, "LC", 1907 (2), pp. 209-18. (Fr. Pedro fue guardian del convento de Northampton).

${ }^{97}$ Atanasio LÓPEZ FERnÁndez, OFM. Primicias franciscanas en España. Fr. Esteban Alonso Dominguez. Fr. Juan, lector de León. "LC". 1908 (2), pp. 49-55. (Fr. Juan fue enterrado en el convento de Lisboa).
} 


\section{FRANCISCANISMO Y MONARQUÍA}

Al igual que mencionábamos un poco más arriba, el protagonismo de los miembros de la orden franciscana no sólo se va a dejar sentir en los estratos más inferiores de la sociedad, sino que su presencia va a ser muy palpable en el seno de la propia corte regia. Una presencia, puesta de manifiesto, debido al influjo tan importante que van a tener los frailes franciscanos sobre los distintos monarcas castellanos de la época, en materia de espiritualidad y, sobre todo, de dirección de conciencias.

Así, vemos cómo, desde los primeros momentos de aparición de esta nueva orden, los monarcas castellanos se van a rodear de estos frailes mendicantes para situarlos como confesores personales y ayos o maestros de los infantes, tomando una enorme relevancia la labor que van a ejercer como preceptores reales dando lugar a la plasmación de estas enseñanzas mediante la creación de tratados que tomarán la forma de los conocidos "Espejos de príncipes" que muestran como debe ser la educación más adecuada para los infantes. ${ }^{98}$ Esta posición de confesores regios les reportarán, a los miembros de la orden de los Menores, una situación de especial preponderancia sobre las iniciativas más directas y personales de los monarcas castellanos, así como de la obtención de mayores beneficios y privilegios para su propia orden.

Debido a estos antecedentes, la bibliografía que existe al respecto es bastante generosa aunque, en la mayoría de los casos, bastante antigua. Para el tema de los confesores reales en la corte castellana del siglo XIII, es inevitable mencionar al omnipresente P. Atanasio López $^{99}$, autor permanentemente presente en la mayoría de las líneas de investigación referentes a este siglo, y al P. Manuel de Castro ${ }^{100}$. Pero, aún habiendo bibliografía referente a este tema, se echa de menos la existencia de trabajos monográficos sobre algún confesor en particular para este período cronológico, y así completar los estudios ya realizados para otros confesores de la familia real

\footnotetext{
${ }^{98}$ Un buen ejemplo lo tenemos en la figura de Fr. Juan Gil de Zamora, preceptor del futuro Sancho IV y creador de la obra De preconiis Hispaniae, dedicada al propio infante y que actuará a modo de tratado para la enseñanza del heredero al trono. (Para un mayor conocimiento de este personaje y esta obra consultar el trabajo del P. Manuel de Castro citado en la nota 80).

${ }^{99}$ Atanasio López Fernández, OFM, Confesores de la familia real de Castilla, "AIA", XXXI (1929), pp. 6-75.

${ }^{100}$ Manuel de CASTRO y CASTRO, OFM, Confesores franciscanos de los reyes de España, “DHEES", pp. 219-21.
} 
como fueron los efectuados para Fernando de Illescas ${ }^{101}$ y Alfonso de Alcocer ${ }^{102}$, relativos a los siglos XIV y XV.

Esta presencia franciscana en la corte castellana, como confesores reales y su influjo en el propio círculo cortesano, se vería rápidamente correspondida por parte de la monarquía. Esta correspondencia se saldaría, por un lado, en la multiplicación de diversos privilegios a favor de la orden franciscana por iniciativa del rey Sancho IV de Castilla ${ }^{103}$ y de su hijo, Fernando IV $^{104}$; y por otro, en una intensa devoción franciscana experimentada por los propios monarcas y por el círculo cortesano. En este aspecto, son de reseñar los artículos del P. Atanasio López ${ }^{105}$ y de Salustiano Moreta Velayos ${ }^{106}$ para el caso particular de Sancho IV y su esposa, María de Molina. Esta fuerte devoción se impregnaría en todas las etapas de la vida del monarca y, fundamentalmente, en el tránsito de la vida a la muerte, quedando plasmada materialmente en la erección de tumbas o túmulos funerarios, convirtiéndose, como sucede con el sepulcro de Sancho IV de Castilla, en un símbolo de la humildad, fiel reflejo del influjo franciscano en la persona del propio monarca castellano ${ }^{107}$.

\footnotetext{
${ }^{101}$ Atanasio LÓPEZ FERnÁNDEZ, OFM, Fray Fernando de Illescas, confesor de los Reyes de Castilla Juan I y Enrique III, "AIA", XXX (1928), pp. 241-252.

${ }^{102}$ Atanasio LÓPEZ FERNÁNDEZ, OFM, Fray Alfonso de Alcocer, confesor de Enrique III de Castilla, "AIA", XXX (1928), pp. 369-374.

${ }^{103}$ Luis CARrión, OFM, Privilegio del rey Sancho IV, el Bravo, a los franciscanos (Soria 20.II.1285), "AIA", V (1916), pp. 127-31. Manuel RODRíGUEZ PAZOS, OFM, Privilegios de Sancho IV a los franciscanos de la provincia de Santiago (1284), y de Castilla (1285), "AIA", XXXVI (1976), pp. 529-52.

${ }^{104}$ Atanasio LÓPEZ FERNÁNDEZ, OFM, Documentos regios a favor de la provincia de Santiago, "LC", 1911 (2), pp. 257-66. (De Sancho IV, 1284; Fernando IV y Alfonso XI, 10.VIII.1326, a instancias del provincial Fr. Domingo).

${ }^{105}$ Atanasio LÓPEZ FERNÁNDEZ, OFM, Devoción de la familia real de España a san Francisco y su orden, "EF", XLIII (1926), pp. 631-33. La familia real de Castilla y los franciscanos, "EF", L (1933), pp. 536-37 y 563-65.

${ }^{106}$ Salustiano MORETA VELAYOS, Notas sobre el franciscanismo y el dominicanismo de Sancho IV y María de Molina, "Actas de la VI a Semana de Estudios Medievales (Nájera, 1995)", Logroño, 1996, pp. 171-184.

${ }^{107}$ M. NUÑEZ RodRíGUEZ, Iconografía de humildad: el yacente Sancho IV, "Boletín del Museo Arqueológico Nacional”, III (1985), pp. 169-175.
} 


\section{Apostolado y Misiones Franciscanas}

Será en este aspecto donde la aparición de las ordenes mendicantes producirán su mayor aportación. Ahora, el papel del fraile como propagador del mensaje divino alcanzará una importancia sin precedentes. Una predicación que tomará un nuevo rumbo, antes desconocido, en el que la palabra será comprendida y asimilada por todo el locutorio de fieles. Se rompe con un mensaje discriminador, solamente accesible a un público erudito conocedor de la lengua latina que restringía claramente su difusión del mensaje para el resto del auditorio, desposeído del conocimiento de esa lengua latina. Ahora se empieza a utilizar como lengua de predicación la lengua vernácula y, por lo tanto, para el caso concreto castellano, la lengua castellana como vehículo propagador de unas ideas. La importancia de esta actividad de apostolado será tal, que incluso se verá afectada la planta y estructura de los propios edificios conventuales, otorgando una situación de predilección al espacio que van a ocupar los fieles, dando lugar a la proliferación de edificios de planta única, aunque esto no impedirá que se ejecuten otro tipo de plantas.

Además de esta importantísima misión de apostolado, desarrollada en las distintas ciudades y villas castellanas, también van a aportar una destacada labor misionera, poniendo, si fuera necesario para lograr sus objetivos, sus vidas en peligro. Esta actividad misionera será la razón de ser de estos frailes franciscanos, ya expresada claramente en su denominación de "mendicantes", siendo los principales propagadores de la nueva espiritualidad que será la que oriente el rumbo de las mentalidades religiosas en la Baja Edad Media y de la que pretenderán hacer partícipes, no sólo a los creyentes cristianos, sino también a los que no lo son. En tierras castellanas, la situación tendrá un claro matiz diferenciador, en relación con el resto de Europa, debido a la proximidad con los musulmanes. Por este motivo, estas iniciativas misioneras se localizarán, fundamentalmente, en territorio de $\mathrm{Al}$-Andalus y, desde aquí, cruzarán el Estrecho, adentrándose en tierras del norte de África. Aunque el desarrollo de estas misiones será muy destacable para este siglo, no alcanzarán su máximo apogeo hasta el siglo XVI, en el que, con el descubrimiento de América y de nuevas tierras en el Pacífico, se abrirán nuevas puertas de expansión y difusión para estas labores misioneras.

Pero como se ha podido ver con otras líneas de investigación, para los estudios del apostolado en la Castilla del siglo XIII carecemos de trabajos 
basados en este importante tema, no sólo para alguna provincia franciscana o zona concreta de difusión franciscana, sino para Castilla en general. Únicamente, se puede citar como pauta para iniciarse en este ámbito de trabajo la obra de Carlos Faulhaber ${ }^{108}$ tratando el tema de las retóricas hispanolatinas.

Sin embargo, referido a la temática de las misiones franciscanas podemos disfrutar de unos cimientos mucho más sólidos para abordar el estudio de esta faceta de la labor franciscana con mayores garantías de éxito, ya que la producción bibliográfica desarrollada, aunque no muy amplia, si está más centrada en el ámbito geográfico que nos ocupa en este momento. Así, para la labor misionera en territorio castellano, hay que resaltar la obra del P. Atanasio López ${ }^{109}$; mientras que sobre las misiones en territorio norteafricano están los trabajos de los PP. Manuel Pablo Castellanos ${ }^{110}$ y Enrique Koehler ${ }^{111}$ dándonos una brillante interpretación, en sus respectivas investigaciones, de este apostolado misionero franciscano en territorio marroquí.

\section{LA SEGUNDA ORDEN FRANCISCANA EN CASTILla: LAS CLARISAS}

Como es obvio, toda transformación producida en el seno de la Iglesia, como puede ser el caso presente de la aparición de nuevas ordenes religiosas, no afecta únicamente al sector masculino de la población, sino que, por el contrario, es acompañado y complementado por el sector femenino en esta nueva espiritualidad que se viene forjando desde el siglo XIII. Para el fenómeno franciscano, este tendrá su réplica femenina con la aparición de la "Segunda orden franciscana" u "Orden de Santa Clara"

\footnotetext{
${ }^{108}$ Carlos FAULHABER, Las retóricas hispanolatinas medievales (siglos XIII-XV), "RHCEE", VII (1979), pp. 13-65.

${ }^{109}$ Atanasio LÓPEZ FERNÁNDEZ, OFM, Cruzada contra los sarracenos en el reino dè Castilla predicada por los franciscanos de la provincia de Santiago, "AIA", IX (1918), pp. 321-27 (predicada por Fr. Juan Martínez, obispo de Cádiz, 1275). "LC", 1911 (2), pp. 250-57.

${ }^{110}$ Manuel Pablo CASTEllanos, OFM, Apostolado seráfico en Marruecos, o sea, historia de las misiones franciscanas en aquel imperio desde el siglo XIII hasta nuestros días, Madrid, 1896.

'"'Enrique KOEHLER, OFM, L'église chrétienne du Maroc et la mission franciscaine, 12211790, París, 1934, XXXII.
} 
(O.S.C.), nombre dado en recuerdo de su fundadora, Clara Favarone, teniendo una profunda vinculación desde sus orígenes con los frailes menores, de tal manera que primero encontraremos un convento de franciscanos y sólo después aparecerá, en las proximidades, una comunidad de la O.S.C. Si los conventos masculinos presentan desde el principio una evidente vocación urbana, que los aleja del ideal de aislamiento monástico altomedieval, también las clarisas se instalarán, como ellos, en las ciudades, de acuerdo con el espíritu de su época ${ }^{112}$.

Afortunadamente, para la temática clariana, sí disponemos de una variada y, lo que es más importante, actualizada bibliografía que nos ofrece una amplia visión de lo que es el fenómeno de la instalación de la O.S.C. en Castilla y su ulterior desarrollo en la misma. En este aspecto, es fundamental hacer una mención muy especial a la celebración del "Congreso Internacional: Las Clarisas en España y Portugal. Salamanca, 20-25 de septiembre de 1993" por lo que ha supuesto para el conocimiento de esta rama de la orden franciscana en España; así como, de la celebración, en Nájera, de la "VI Semana de Estudios Medievales, 1996", ocupándose de lleno en el franciscanismo peninsular medieval y, muy especialmente, en sus orígenes; refiriéndose también, como es lógico, al sector femenino de la orden.

A la hora de enfrentarse a esta línea de investigación, es necesario conocer la bibliografía más reciente que existe sobre la misma. Para ello se hace imprescindible manejar las recopilaciones bibliográficas del ya mencionado P. Manuel de Castro ${ }^{113}$, muy general, $y$, mucho más específica sobre clarisas, de García de la Herrán Muñoz ${ }^{114}$.

Los autores que tratarán con más profundidad la instalación de las clarisas en Castilla, utilizando un análisis globalizador, serán los PP. Omaechevarría $^{115}$ y García Oro ${ }^{116}$, y Clara Rodríguez Nuñez ${ }^{117}$, que,

\footnotetext{
"Clara RodRiguez NuÑEZ, El conventualismo femenino: Las clarisas, "Actas de la VI" Semana de Estudios Medievales (Nájera, 1995)", Logroño, 1996, p. 99.

${ }^{113}$ CASTRO Y CASTRO, OFM, Bibliografía hispanofranciscana..

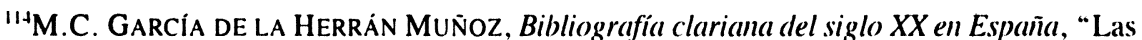
clarisas en España y Portugal. Congreso Internacional, Salamanca, 20-25 de septiembre de 1993", Actas I, Vol. I, pp. 3-61.

"115. Ignacio OMAECheVARRía, OFM, Las clarisas a través de los siglos, Madrid, 1972.

"16José García ORO, OFM, Orígenes de las clarisas en España, "Las clarisas en España y Portugal. Congreso Internacional, Salamanca, 20-25 de septiembre de 1993", Actas II, Vol. I, pp. 163-182.

${ }^{117}$ Clara Rodríguez NuÑEZ, El conventualismo femenino. pp. 87-100
} 
a manera de síntesis, ofrecerán una clara exposición de cómo, cuándo y dónde se producirán estos asentamientos de monjas clarisas en territorio peninsular, así como de los avatares que tuvieron que sufrir hasta su definitiva instalación.

Al igual que ocurre con el sector masculino de la orden, la bibliografía aparecida sobre los distintos conventos femeninos es muy extensa, ya que prácticamente todos los conventos femeninos tienen su propia bibliografía; algunos trabajos realizados por historiadores más o menos profesionales y otros trabajos elaborados por eruditos locales, no por ello menos válidos. Si se pretende disponer de un punto de partida para conocer los distintos asentamientos clarianos en la Península con cierta solidez, es imprescindible consultar la obra del P. Atanasio López ${ }^{118}$, Moorman $^{119}$ y de los PP. Manuel de Castro ${ }^{120}$ y Omaechevarría ${ }^{121}$, poniéndonos al corriente de los distintos conventos de clarisas que surgirán en la Península en el siglo XIII y sus primeros momentos de existencia.

Ubicándonos en zonas geográficas más concretas, son importantes los estudios realizados para el área de la Provincia Franciscana de Santiago por el P. Castro ${ }^{122}$ y Rodríguez Nuñez ${ }^{123}$. Mientras, para el área Vasca, estaría la obra del P. Uribe ${ }^{124}$; para Castilla la Nueva, Muñoz Fernán-

\footnotetext{
${ }^{118}$ Atanasio LÓPEZ FERNÁNDEZ, OFM, Los monasterios de clarisas en España en el siglo XIII (1212-1300), “EF”, XXIX (1912), pp. 185-190.

${ }^{119}$ MOORMAN, Medieval Franciscan, pp. 535-688.

${ }^{120}$ Manuel de CASTRO Y CASTRO, OFM, Monasterios hispánicos de clarisas desde el siglo XIII al XVI, “AIA", XLIX (1989), pp. 79-122.

${ }^{121}$ Ignacio OMAECHEV ARRÍA, OFM, Primeros monasterios de clarisas en España con ocasión de los 750 años de vida de la comunidad de Santa Engracia de Olite, Soria, 1978.

${ }^{122}$ Manuel de CASTRO Y CASTRO, OFM, Los conventos de clarisas de la provincia de Santiago, "EF", LXX (1953), pp. 246-50, 266-69 y 273.

${ }^{123}$ Clara Rodríguez NuÑEZ, Los conventos femeninos en Galicia. El papel de la mujer en la sociedad medieval, Lugo, 1993.

${ }^{124}$ Ángel URIBE, OFM, Asentamientos y expansión de la orden de Santa Clara en el País Vasco, "AIA", LIV-I (1994), pp. 233-256.
} 
dez ${ }^{125}$; y para la zona de Andalucía, las obras de Graña $\operatorname{Cid}^{126}$ y de Miura Andrades ${ }^{127}$.

En la temática conventual individual, propiamente dicha, el elenco de autores es muy amplio, destacando a los ya clásicos PP. Atanasio López $^{128}$, Castroo ${ }^{129}$, Vázquez ${ }^{130}$ y Omaechevarría ${ }^{131}$. Otros autores que también se han dedicado a mostrarnos la génesis y desarrollo de los distintos conventos de clarisas en Castilla son Conde-Valvi ${ }^{132}$, Villalba Ruiz $^{133}$, Enrique Gutiérrez ${ }^{134}$, Balbino Velasco ${ }^{135}$, Ruiz de Larrina-

\footnotetext{
${ }^{125}$ Angela MUÑoz FERNÁNDEZ, Las clarisas en Castilla la Nueva. Apuntes para un modelo de implantación regional de las órdenes femeninas franciscanas (1247-1600), "AIA", LIV-I (1994), pp. 455-472.

${ }^{126} \mathrm{M}^{\mathrm{a}}$ del Mar Graña CID, Las primeras clarisas andaluzas. Franciscanismo femenino $y$ reconquista en el siglo XIII, "AIA", LIV-II (1994), pp. 661-704.

${ }^{127}$ Jose $M^{\mathrm{a}}$ MIURA ANDRADES, Las fundaciones de clarisas en Andalucía del siglo xiii a 1525, "AIA", LIV-II (1994), pp. 705-722.

${ }^{128}$ Atanasio LÓPEZ FERNÁNDEZ, OFM, Monasterio de Santa Clara, de Alcocer (ant. 1260) (a continuación del título se indicará el año de fundación o del primer documento que hace mención de la existencia de dicho convento), "EFr", VII (1911), pp. 408-14. Convento de Santa Clara de Allariz, (1282) "EFr", VIII (1912), pp. 281-84, 380-87; IX (1912), pp. 132-41. "AFH", V (1912), pp. 808-809. Convento de Santa Clara de Pontevedra, (1271), "EFr", XII (1914), pp. 45-55. Convento de Santa Clara de Toledo, (1250), "EFr", VII (1911), pp. 327-31. Monasterio de Santa Clara de Toro, (1258), "EFr", VIII (1912), pp. 55-60. "AFH", V (1912), pp. 807-808.

${ }^{129}$ Manuel de CASTRO Y CASTRO, OFM, Monasterio de Santa Clara, de Astorga, (1258), "BRAH”, CLXXXV (1988), pp. 235-326. Fundación del convento de Santa Clara, de Burgos. Documentos de los siglos XIII al XVI (1234), "BRAH", CLXXI (1974), pp. 137-93. Santa Clara de Pontevedra. Notas para su estudio, "AIA", LIV-II (1994), pp. 879-906. El real monasterio de Santa Clara, de Santiago de Compostela, (c.1260), "AIA", XLIII (1983), pp. 3-61. (Con apéndice documental).

${ }^{130}$ Isaac VÁZQUEZ JANEIRO, OFM, ¿De quién fue hija la princesa Berenguela que fundó el monasterio de Santa Clara de Toro, y én él reposa?, "Ant”, LII (1977), pp. 359-94.

${ }^{131}$ Ignacio OMAEChEVARRÍA, OFM, Orígenes del monasterio de Santa Clara de Zamora (1229), "AIA", XLIV (1984), pp. 483-92.

${ }^{132} \mathrm{~F}$. CONDE-VALVI FERNÁNDEZ, Doña Violante, reina de Castilla, está enterrada en Allariz, "BCMO", XCII (1950), pp. 179-188.

${ }^{133} \mathrm{~F}$. J. VILLALBA RUIZ DE TOLEDO, El monasterio de Santa Clara de Alcocer y su conexión con la monarquía (siglos XIII-XVI), "Wad-al-Hayara”, XVI (1989), pp. 319-326.

${ }^{134}$ Enrique GUTIÉRREZ, OFM, Monasterio de Santa Clara, de Burgos, DCCL aniversario de la fundación, Burgos, 1985.
}

${ }^{135}$ Balbino VelasCo, OC, El convento de Santa Clara de Cuéllar, (1244), "AIA", XXXIII (1973), pp. 269-270; XXXIV (1974), pp. 457-82. 
ga $^{136}$, Martínez Moreno ${ }^{137}$, Torres Fontes ${ }^{138}$, Sánchez Gil ${ }^{139}$, Ajo $^{140}$, Riesco Terrero ${ }^{141}$, Cardeñoso ${ }^{142}$, Valdivieso y Morales ${ }^{143}$, Pérez de Tudela ${ }^{144}$, Navarro ${ }^{145}$, Sarasola ${ }^{146}$ y otros $^{147}$.

Un aspecto que no se puede dejar pasar por alto es el referido a la organización legislativa de la Segunda Orden. Al igual que para la Primera Orden, las clarisas tenían perfectamente regulada su vida interna en los conventos. Una regulación legislativa basada en Constituciones, elaboradas y modificadas a lo largo del siglo XIII. Entre estas destacarán la adoptada en 1218 por el cardenal Hugolino - futuro papa Gregorio IX -, la creada por la propia santa Clara y aprobada en 1253 , y la promulgada por Urbano IV en 1263. Las clarisas españolas tomarán de forma mayoritaria esta regla urbanita, aunque los conventos que habían sido fundados con anterioridad a 1263 habían conocido, como es natural, otras legislaciones ${ }^{148}$. En esta línea de investigación, la bibliografía que poseemos es muy parca y solamente nos podemos referir a obras que, aunque situando sus estudios en el siglo XIII,

\footnotetext{
${ }^{136}$ J. Ruiz De Larrinaga, Santa Clara de Allariz. Historia y vida de un monasterio, Santiago de Compostela, Liceo Franciscano, 1990. Santa Clara de Allariz. Séptimo centenario de su fundación, "Boletín Aurense", V (1986).

${ }^{1.37} \mathrm{M}^{\mathrm{a}}$ Luisa MARTínez MORENO, OSC, Santa Clara-Hellin (Historia del monasterio), $1253-$ 1953. (1253), Hellín, 1984.

${ }^{138}$ Juan TORRES FONTES, El monasterio de Santa Clara la Real de Murcia (siglos XIII y XIV) (1266), "Mur", XX (1963), pp. 87-104.

${ }^{139}$ Víctor SÁnChEZ GIL, OFM, Santa Clara la Real de Murcia, siglos XIII-XIX. Documentos para su historia, "AIA", LIV-II (1994), pp. 847-878.

${ }^{1+1}$ Cándido AJo Y SANZ DE ZÚÑIGA, El real convento de Santa Clara (de Rapariegos), (1287), "Estudios Abulenses", III (1955), pp. 75-87.

i'Ángel Riesco Terrero, Datos para la historia del real convento de clarisas de Salamanca. Catálogo documental de su archivo, (1238), León, 1977.

${ }^{1+2} \mathrm{~L}$. Cardeñoso, Convento de San Antonio de religiosas clarisas de Segovia (c. 1281), "AIA", VII (1917), pp. 5-26; VIII (1917), pp. 321-349.

${ }^{1+3}$ E. Valdivieso González y A. J. Morales Martínez, Sevilla oculta. Monasterios y conventos de clausura, Sevilla, 1980.

${ }^{1+1} \mathrm{M}^{a}$ Luisa PÉrez de TUdela y BUESO. El convento de Santa Clara la Real de Toledo (1247-1993), "AIA", LIV-I (1994), pp. 485-510.

${ }^{145}$ José Navarro Talegón, La fundación del real monasterio de Santa Clara de Toro, "AIA", LIV-I (1994), pp. 301-316.

${ }^{1+6}$ Modesto SaraSOLA, OFM, El siglo XIII en Valladolid. Origen del convento de Santa Clara, Valladolid, 1960. (Con apéndice documental).

${ }^{147}$ VV.AA., VII Centenario de las clarisas de Soria, Soria, 1986.

${ }^{1+8}$ Clara Rodríguez NUÑEZ, El conventualismo femenino, pp. 90-92.
} 
se preocupan de aspectos más globales, dejando un poco de lado su aplicación concreta a una provincia o área geográfica definida. De esta manera, tenemos el trabajo del P. Antonio García y García ${ }^{149}$ con su estudio histórico-jurídico clariano; y centrándose más en la "forma vitae" hugoliana, estarían los PP. Isaac Vázquez ${ }^{150}$ e Ignacio Omaechevarría ${ }^{151}$.

Para finalizar este apartado, es importante hacer hincapié en la intensa relación que tuvo la Orden de Santa Clara con la realeza castellana de la época. Esta no fue tan bilateral como ocurre con la Primera Orden, ya que, como vimos, importantes personalidades de la orden pasarían a formar parte de las personas de confianza del monarca, ejerciendo labores de confesores, consejeros, ayos, etc. Por el contrario, la relación realezaclarisas fue mas unilateral; es decir, que los contactos fueron más por parte de los propios monarcas, debido a su intensa devoción, que a intervenciones de miembros clarianos en actividades próximas a la corte; esto provocaría una intervención muy directa en toda una serie de fundaciones femeninas en todo el territorio castellano, incluso llegando a contagiar esta actividad fundadora a la nobleza, como pone de manifiesto Cavero Domínguez ${ }^{152}$. También hay algunas obras, dedicadas a algún convento en particular, que destacan esta devoción por las clarisas por parte de la realeza. Entre estas hay que señalar a las realizadas por Conde-Valvi ${ }^{153}$, Villalba Ruiz ${ }^{154}$ y el P. Vázquez ${ }^{155}$, anteriormente citadas. Quizás, esta sea una línea de investigación a tener muy en cuenta, ya que, en este campo, la bibliografía no es muy amplia y, tal vez, si se indagara más en los archivos conventuales se pudiera sacar más información al respecto, incluso encontrándonos con agradables sorpresas.

\footnotetext{
${ }^{1+9}$ Antonio García Y García. OFM, La legislación de las clarisas. Estudio históricojurídico, "AIA", LIV-I (1994), pp. 183-198.

${ }^{150}$ Isaac VÁzQUEZ JANEIRO. OFM, La "forma vitae" hugoliana para las clarisas en una bula desconocida de 1245, "Ant". LII (1977), pp. 94-125

${ }^{151}$ Ignacio OMAECHEVARRÍA, OFM, Nueva valoración de la "forma vitae" del cardenal Hugolino, "Ant", LIII (1978), pp. 343-346.

${ }^{152}$ Gregoria CAVERo Dominguez, Monarquía y nobleza: su contribución a las fundaciones de clarisas en Castilla y León (siglos XIII-XV), "AIA", LIV-I (1994), pp. 257-280.

${ }^{15.3} \mathrm{~F}$. CONDE-VAlvi Fernández, Doña Violante, reina de Castilla. Op. cit.

${ }^{154}$ F.J. Villalba Ruiz de Toledo, El monasterio de Santa Clara de Alcocer. Op. cit.

${ }^{155}$ Isaac VAzQUEZ JANEIRO, OFM, ¿De quién fue hija la princesa Berenguela. Op. cit.
} 


\section{LA TERCERA ORDEN FRANCISCANA SEGLAR EN CASTILLA (O.F.S.)}

La renovadora espiritualidad que se generará con la llegada a la Península de la orden franciscana, afectará, como ya hemos visto al tratar de la bibliografía de la Primera Orden, a todas las capas de la sociedad castellana. Esta nueva espiritualidad no será coto cerrado y exclusivo del cuerpo eclesiástico, sino que la población laica también deseará hacerse partícipe de la misma y, de esta manera, poder satisfacer sus necesidades espirituales y beneficiarse de la recompensa que obtendrán al abandonar este mundo. Por este motivo, al ser la orden de los frailes menores tan próxima a todas las capas sociales se crearán una serie de agrupaciones de seglares que, sin abandonar esta condición, desean aproximarse mucho más a este nuevo ideal de vida religiosa que profesan los frailes franciscanos, lo que provocará la formación de una Tercera orden franciscana seglar (O.F.S.), también llamada "de Penitencia".

La producción bibliográfica que se ocupará sobre esta línea de investigación, para este reino y época, está prácticamente en pañales. Disponemos de algunos trabajos de carácter general que nos informan sobre su aparición y formación, ya desde tiempos de san Francisco de Asís ${ }^{156}$. Mientras que para todo lo concerniente a la aparición de los Terciarios en la Castilla del siglo XIII sólo disponemos de pequeños estudios, que son los que nos ofrecen los PP. Rodríguez de Legísima ${ }^{157}$ y Villapadierna ${ }^{158}$, pero su estudio es también de carácter general para toda la Península.

Como es lógico, al formar parte de una orden religiosa, su participación en la misma, como terciarios, estará regulada legislativamente siguiendo las misma constituciones, aunque con algunas variantes, que dirigen la vida de la Orden Primera. Para acercarnos a esta problemática del derecho particular de la Orden Tercera puede ser de mucha ayuda el trabajo

\footnotetext{
${ }^{156}$ Fredegando de AMBERES, OFM CAP., La tercera orden secular de San Francisco (12211921), Madrid, 1925. J. V. CIURANA, La orden de penitencia de san Francisco. Notas sobre sus origenes y desarrollo en el siglo XIII, "Selecciones de Franciscanismo", VII (1979), pp. 1954.

157Juan RodRíguez DE LEGÍsIMA, OFM, Crónica del Congreso Nacional de terciarios franciscanos, celebrado en Madrid del 16 al 20 de mayo de 1914, en el VII Centenario de la venida de San Francisco a España, Madrid, 1915.

${ }^{158}$ Isidoro de VILlaPADIERNA, OFM CAP., Observaciones críticas sobre la Tercera Orden de Penitencia en España (siglo XIII), "CF”, XLIII (1973), pp. 219-27.
} 
de Heriberto Roggen ${ }^{159}$, realizando un buen estudio sobre la misma, deteniéndose en las relaciones contraidas entre la Primera Orden y los Terciarios en el siglo XIII en materia de legislación, pero siempre desde una óptica muy general.

\section{ARTe, Poesía y MÚsica}

La nueva espiritualidad implantada en Castilla, debido a la penetración de la Orden de los Frailes Menores, conllevará toda una serie de manifestaciones de carácter artístico, literario y musical que resaltarán, aún más si cabe, este ambiente de renovación espiritual y religioso.

En el plano artístico, disponemos de trabajos que nos muestran una visión de conjunto del arte franciscano en España. Entre otros, hay que destacar los realizados por los PP. Zamora ${ }^{160}$ y Castro $^{161}$, al igual que la tesis doctoral realizada por $\mathrm{M}^{\mathrm{a}}$ Raquel Alonso Alvarez ${ }^{162}$ sobre el arte franciscano en ámbito asturiano. Los cambios estructurales en el campo arquitectónico no serán muy llamativos debido a que, en este siglo, se detecta una ausencia total de arquitectura ya que los frailes solían ocupar casas donadas generalmente por particulares o bien ermitas u hospitales inutilizados desde donde realizaban su labor de apostolado. No se producirán manifestaciones arquitectónicas, propiamente franciscanas, hasta muy entrado el siglo XIII, lo que supondría, como diría Marta Cuadrado, "una evidente "traición" a los primitivos ideales de estas órdenes y muy especialmente al espíritu de sus fundadores"163. La bibliografía existente relacionada con este tema de la arquitectura franciscana ha sufrido, afortunadamente, una

\footnotetext{
${ }^{159}$ Heriberto RoGGEN, Relaciones de la orden franciscana con la tercera orden en el siglo XIII, “CFR", XI (1978), pp. 110-114.

${ }^{160}$ Germán ZAMORA, OFM CAP., Historia gráfica de 800 años de franciscanismo. Las exposiciones del VIII Centenario, "CF", LIII (1983), pp. 361-402.

${ }^{16 l}$ Manuel de CASTRO Y CASTRO, OFM, El arte franciscano en España durante los siglos XIII-XVI, "VV", L (1992), pp. 393-449.

${ }^{162} \mathrm{M}^{\mathrm{a}}$ Raquel Alonso Alvarez, El arte de los franciscanos y las clarisas en Asturias. De la fundación a la Desamortización, tesis doctoral dirigida por $\mathrm{M}^{\mathrm{a}}$ Soledad Alvarez Martinez y presentada en la Facultad de Geografía e Historia de la Universidad de Oviedo en el curso 93 94.

${ }^{163}$ Marta CUADRADO SÁNCHEZ, Un nuevo marco socioespacial: emplazamiento de los conventos mendicantes en el plano urbano, "Actas de la VI ${ }^{\mathrm{a}}$ Semana de Estudios Medievales (Nájera, 1995)", Logroño, 1996, pp. 102-3.
} 
revisión muy seria debido al trabajo de Marta Cuadrado Sánchez ${ }^{164}$, de imprescindible consulta para el tema que nos ocupa, llegando a satisfacer un llamativo vacío historiográfico. Junto a esta autora, también hay que citar al Conde de Cedillo ${ }^{165}$, y mucho más actuales, a Martínez de Aguirre ${ }^{166}$ y Castillo Utrilla ${ }^{167}$. Tampoco podemos olvidarnos de las grandes colecciones de arte español y los trabajos allí impresos de Torres Balbas ${ }^{168}$, Chueca Goitia $^{169}$ y Yarza Luaces ${ }^{170}$, que nos ofrecen unos estudios muy pormenorizados y sintéticos de la producción arquitectónica franciscana en suelo peninsular en la Baja Edad Media.

$\mathrm{Si}$ para la bibliografía referente a la arquitectura franciscana disponemos de trabajos que nos acerquen a esta línea de investigación, no va a ocurrir lo mismo para la escultura, pintura y artes menores con temática franciscana. Solamente disponemos de pocos trabajos, realizados en los dos primeros decenios del presente siglo, con un marcado carácter general y de síntesis, y susceptibles de una intensa revisión. Así, para la escultura con temática franciscana destacaríamos a Castillo-Olivares ${ }^{171}$ y Sánchez

\footnotetext{
${ }^{16+}$ Marta CUADRADo SÁNCHEZ, Arquitectura franciscana en España (siglos XIII y XIV), "AIA". LI (1991), pp. 15-70 y 479-552, planos. Realizó un resumen de sus estudios en Arquitectura de las órdenes mendicantes, "Cuadernos de Arte Español Historia 16", LXXXVI. Madrid, 1993.

${ }^{165}$ CONDE DE CEDILLO, La arquitectura franciscana en España, "ExpFran”, pp. 117-32.

${ }^{166}$ Javier MARTINEZ DE AGUIRRE, Espiritualidad franciscana y arquitectura gótica: Del recelo a la reavitalización. "Actas de la VI ${ }^{a}$ Semana de Estudios Medievales (Nájera, 1995)", Logroño, 1996, pp. 111-131.

${ }^{167} \mathrm{M}^{\mathrm{a}}$ José del CASTILLO UTRILLA. Tipología de la arquitectura franciscana española desde la Edad Media hasta el Renacimiento, "Actas del Congreso de Historia del Arte", Vol. I, Granada, 1973, pp. 323-327.

${ }^{168}$ L. TORRES BALBAS, Arquitectura gótica, "Ars Hispaniae. Historia del Arte Hispánico", Madrid, 1957, pp. 120-30 y 222-24. (Hace más hincapié en Cataluña).

${ }^{169}$ Fernando ChUECA GoITIA, Historia de la arquitectura española. Edad Antigua y Media, Madrid, 1965, pp. 360-69.

${ }^{170}$ Joaquín YARZa LUACES, La Edad Media, "Historia del arte hispánico", Vol. II, Madrid. 1978, pp. 224-25. 115.

${ }^{177}$ Pedro del Castillo-Olivares, La escultura franciscana en España, “ExpFran”, pp. 109-
} 
Cantón ${ }^{172}$, para la pintura al Marqués de Montesa $^{173}$ y para la producción de artes menores, referido a la sigilografía, a Fuente Isla ${ }^{174}$.

En el campo de la producción poética y musical el panorama no es más esclarecedor. No disponemos de obras monográficas que nos puedan dar luz sobre la literatura poética franciscana, que se supone debió de ser muy rica. Únicamente podemos hacer referencia a la obra del P. Samuel Eiján ${ }^{175}$ para tener una visión panorámica de la producción poética desarrollada en la Península Ibérica en el siglo que nos ocupa. No podemos, para la bibliografía musical franciscana, romper con esta línea de llamativa laguna bibliográfica. Desgraciadamente, no existe ningún trabajo, no solamente sobre la música castellana en el siglo XIII, sino que se refiera a la producción musical franciscana en la Península durante la Baja Edad Media. Por este motivo, la única cita bibliográfica que podemos ofrecer es la del trabajo de Isidoro Rodríguez Herrera ${ }^{176}$ referida a la influencia de san Francisco en la música, la cual no nos da una información muy válida para lo que se pretende con este trabajo pero nos puede servir como punto de partida.

\section{CONCLUSIÓN}

A lo largo de este trabajo, hemos podido observar que la cantidad de bibliografía existente para el franciscanismo en la Castilla del siglo XIII es bastante considerable, por lo menos para aproximarnos al estudio del tema propuesto. Aunque, en la actualidad, los temas de franciscanismo parecen que están retomando una nueva vitalidad, lo cierto es que aún nos encontramos con enormes lagunas bibliográficas a la hora de afrontar un tema tan importante como el que nos afecta. Comprobamos que los trabajos sobre la

\footnotetext{
${ }^{172}$ F.J. SÁNCHEZ CANTón, San Francisco de Asís en la escultura medieval española, Madrid, 1926, pp. 6-14.

${ }^{173}$ MARQUÉS de MonTESA, San Francisco en la pintura, “ExpFran”, pp. 77-85 y 99-108.

${ }^{174}$ Benito FUENTE ISLA, La imagen de la Virgen en los sellos. Estudio de sigilografía española de los siglos XIII, XIV y XV, Madrid, 1923.

${ }^{175}$ Samuel EljÁN, OFM, Nuestros juglares del Señor. La poesía franciscana en España, Portugal y América (siglos XIII-XIX). Ensayo histórico-antológico, Santiago de Compostela, 1935, XV.

${ }^{176}$ Isidoro Rodríguez Herrera, San Francisco de Asís en la música y en el arte, "Conferencias pronunciadas en la Fundación Universitaria Española los días 3 de Noviembre de 1976 y 19 de Enero de 1977”, Madrid, 1982.
} 
presencia franciscana en Castilla en el siglo del Rey Sabio, la mayoría, son de producción muy antigua, atendiendo más a temas propiamente de dogma franciscano, espiritualidad y otros más generales que a líneas de investigación que afecten a otras esferas, como pueden ser las relativas a las relaciones de la orden franciscana con la sociedad, su producción cultural, estudios monográficos sobre obispos de procedencia franciscana, presencia franciscana en la corte, estudios prosopográficos, etc. Algunas de estas líneas ya están esbozadas, pero sería muy conveniente revisarlas y ponerlas al día con el fin de realizar estudios en profundidad sobre alguna de estas temáticas propuestas.

Estamos ante unas perspectivas de realización de estudios muy favorables debido, no a la falta de trabajos sobre algún aspecto en concreto del franciscanismo, sino a la enorme posibilidad de retomar temas que, si en un principio han sido tratados, deberían ser actualizados utilizando los nuevos métodos de investigación que poseen los investigadores; teniendo unas perspectivas históricas más amplias, dejando un poco más de lado visiones partidistas e ideológicas que originan una visión histórica parcial y mediatizada. Para evitar esto, es fundamental partir de una adecuada recopilación bibliográfica que nos oriente sobre los distintos trabajos desarrollados, lo más actuales posibles, y, desde aquí, seguir la línea de investigación que más inquietudes nos susciten y en el que las posibilidades de nuevas aportaciones sean mayores. Si con este trabajo hemos conseguido crear esta herramienta tan necesaria para el investigador, la finalidad del mismo se habrá logrado.

\section{RÉSUMÉ}

L'apparition de l'Ordre Franciscain dans le Royaume de Castille se réalisera par l'intermediaire de Francisco de Asis lui-même. Un novel ordre réligieux qui, grâce à la mendicité, se développera et exercera son rôle de guide spirituel de la société sous la protection des centres urbains.

Avec cet article, ce que l'on veut presenter c'est una approche bibliographique de l'Ordre Franciscain médieval de Castille qui nous servira comme un guide à affronter l'étude de la présence franciscaine dans le Royaume de Castille au cours de son premier siécle de gestation.

Avec cet essaie, on tente de donner une bibliographie le plus actuel possible qui mette en vidence les differents champs thématiques dans lesquels l'Ordre des Fréres Mineurs sera present. Cela permettra de mettre en évidence une rélation bibliographique qui aborde 
tout ce qui concerne la mise en oeuvre de l'ordre franciscain en Castille, la création de provences, de monastaires et de convents, le cadre cultural et artistique, la spiritualité, les personnages franciscains les plus répresentatifs et sa rélation avec les groupes dirigéants, etc.

En définitive, il s'agit de réaliser une compilation bibliographique qui nous guide sur le dur chemin de la recherche franciscaine de Castille delimitée comme cela fut affirmé par le "siècle des Frères".

\section{SUMMARY}

The appearance of the Franciscan order in the Kingdom of Castilla will take place under the influence of St Francis of Assisi. A new religious order, which for its mendicant nature, will develops as society's spiritual leader with the help of urban nuclei.

The aim of this article is to offer a detailed bibliography of medieval Castilian Franciscanism and to provide a guide in order to face the study of franciscan presence in the Castiliam Kingdom in its first century.

According to this aim, it is important to show an updated bibliography so as to enlighten the different fields of study in which the Order of Minor Friars will be present. This; offering a bibliographical relationship concerning all the steps of the establishment of the Franciscan Order in Castilla, the creation of provinces, male and female convents, cultural and artistic environment, spirituality, the most out standing franciscan characters and their relationship with the governing groups, etc. Then, presenting a bibliographical compilation which could help the investigation of Franciscan Castile within the frame of "The Century of the Friars". 